\title{
Quality of teaching radiation oncology in Germany-where do we stand?
}

\section{Results from a 2019 survey performed by the working group "young DEGRO" of the German Society of Radiation Oncology}

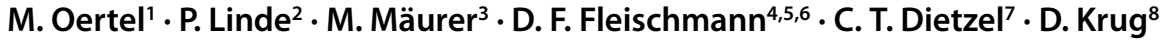 \\ Received: 21 January 2020 / Accepted: 15 April 2020 / Published online: 4 May 2020 \\ (c) The Author(s) 2020
}

\begin{abstract}
Purpose Medical students' knowledge of radiation oncology (RO) is of increasing importance with a rising prevalence of malignancies. However, RO teaching in medical schools is heterogeneous and has not been analyzed at a federal level yet. Therefore, the following survey aims to provide a national overview of RO teaching in Germany.

Methods A questionnaire containing multiple-choice and free-text questions covering the extent and topics of RO teaching was sent to RO departments of all university hospitals in Germany and was answered by the heads of department/main lecturers.

Results 24/35 (68.6\%) RO departments returned completed forms. Most faculties employ lectures (91.7\%), seminars $(87.5 \%)$, and practical/bedside training $(75.0 \%)$, whereas training in radiation biology and medical physics are rare $(25 \%$ and 33.3\%, respectively). Main topics covered are general RO (100\%), radiation biology (91.7\%), and side effects $(87.5 \%)$. Regarding RO techniques and concepts, image-guided and intensity-modulated radiotherapy are taught at all faculties, followed by palliative and stereotactic techniques ( $87.5 \%$ each). Notably, all departments offered at least a partial rotation in RO in conjunction with radiology and/or nuclear medicine departments in the last year of medical school, while only $70.8 \%$ provided a complete rotation in RO. In addition, $57.1 \%$ of the departments have taken measures concerning the upcoming National Competence-Based Learning Objectives Catalogue (NKLM) for medical education.

Conclusion RO plays an integral but underrepresented role in clinical medical education in Germany, but faces new challenges in the development of practical and competence-based education, which will require further innovative and interdisciplinary concepts.
\end{abstract}

Keywords medical education $\cdot$ radiooncology teaching $\cdot$ innovative teaching $\cdot$ competence-based learning $\cdot$ NKLM

Electronic supplementary material The online version of this article (https://doi.org/10.1007/s00066-020-01623-x) contains supplementary material, which is available to authorized users.

M. Oertel, MD

michael.oertel@ukmuenster.de

1 Department of Radiation Oncology, University Hospital Muenster, Muenster, Germany

2 Department of Radiation Oncology and Cyberknife Center, University Hospital of Cologne, Cologne, Germany

3 Department of Radiation Oncology, Jena University Hospital, Jena, Germany
4 Department of Radiation Oncology, University Hospital, LMU Munich, Munich, Germany

5 partner site Munich, German Cancer Consortium (DKTK), Munich, Germany

6 German Cancer Research Center (DKFZ), Heidelberg, Germany

7 Department of Radiation Oncology, University Hospital Halle (Saale), Halle (Saale), Germany

8 Department of Radiation Oncology, University Hospital Schleswig-Holstein, Campus Kiel, Kiel, Germany 


\section{Introduction}

Increasing numbers of patients are diagnosed with cancer each year, reaching an annual incidence of over 450,000 patients in Germany [1]. With around 50\% of oncological patients having an indication for radiation therapy (RT) during their course of disease [2,3], knowledge of radiation oncology (RO) has cardinal importance for both oncological disciplines as well as for general practitioners to provide patients with adequate counsel. However, there are common misbeliefs about RO and its treatment spectrum, which persist until the end of medical school [4], demanding an improvement in teaching. Innovative concepts such as internships or interdisciplinary classes could be of additional value $[4,5]$, but are not obligatory across Germany. At the same time, the introduction of the new German National Competence-Based Learning Objectives Catalogue (NKLM) [6] calls for interdisciplinary and practice-orientated teaching formats. Despite the need for reformed and innovative teaching, a survey by a working group of the German Society of RO (young DEGRO) revealed that only around $20 \%$ of young radiation oncologists are able to perform teaching activities within the regular working hours [7]. The obvious discrepancy between the demand for restructured curricula and the uncertainties concerning formal requirements prompted our working group to perform a survey on the current situation of RO teaching in Germany.

The aim of this study is to describe the state-of-the-art of RO medical education in Germany, to identify potential fields of further development, and to delineate future challenges ahead.

\section{Materials and methods}

A detailed questionnaire assessing extent and topics of RO teaching was designed by the working group of the German Society for RO (young DEGRO) in a peer-review process. The questionnaire contained both open and multiple-choice questions and was sent in written form and/or electronically to all academic RO departments at university hospitals in Germany (see Supplementary 1 for full questionnaire). Answers were analyzed using SurveyMonkey (SurveyMonkey, Dublin, Ireland) and Microsoft Excel for Mac, Version 16.30 (Microsoft Corporation, Redmond, Washington, USA).

\section{Results}

Complete questionnaires were received from 24 out of 35 university hospitals $(68.6 \%)$. In some cases, RO teaching starts in pre-clinical semesters (second semester: 1, third semester: 3), but is found mostly in the second half of medical education during clinical semesters (e.g., fifth semester $37.5 \%$, sixth semester $50 \%$, seventh semester $41.7 \%$, eighth semester $29.2 \%$, ninth semester $45.8 \%$, tenth semester $54.2 \%$; Fig. 1). Teaching is performed by heads of department/directors (100\%), consultants (95.8\%), residents $(91.7 \%)$, and external lecturers $(58.3 \%)$. The predominant teaching formats are lectures $(91.7 \%)$, seminars $(87.5 \%)$, and practical/bedside training $(75.0 \%)$, whereas training in radiation biology and medical physics is less frequent (25\% and $33.3 \%$, respectively). The main topics covered in RO teaching are general RO $(100 \%)$, radiation biology (91.7\%), side effects (87.5\%), and radiation physics
Fig. 1 Responses to the question "During which semesters does radiation oncology teaching take place?" Multiple answers were allowed

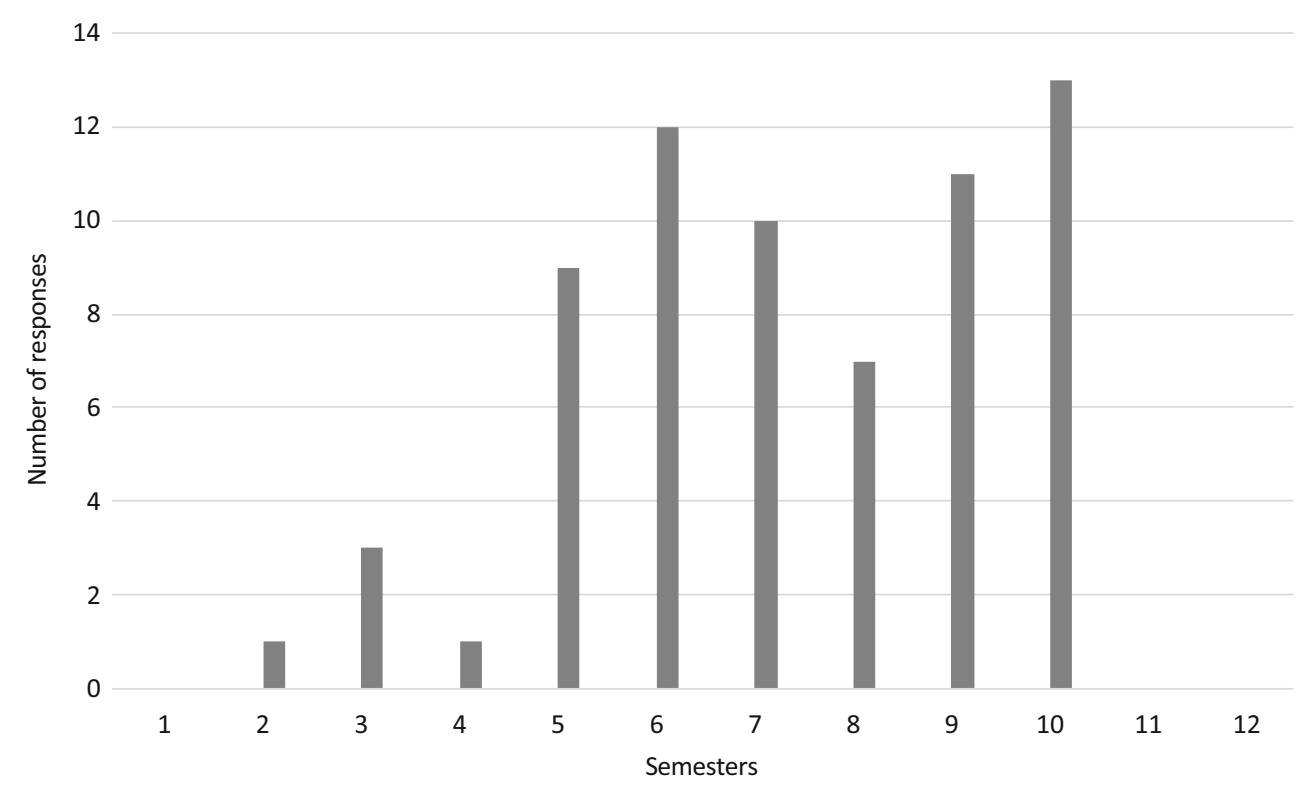


Fig. 2 Responses to the question "Which topics are addressed during radiation oncology teaching?" Multiple answers were allowed
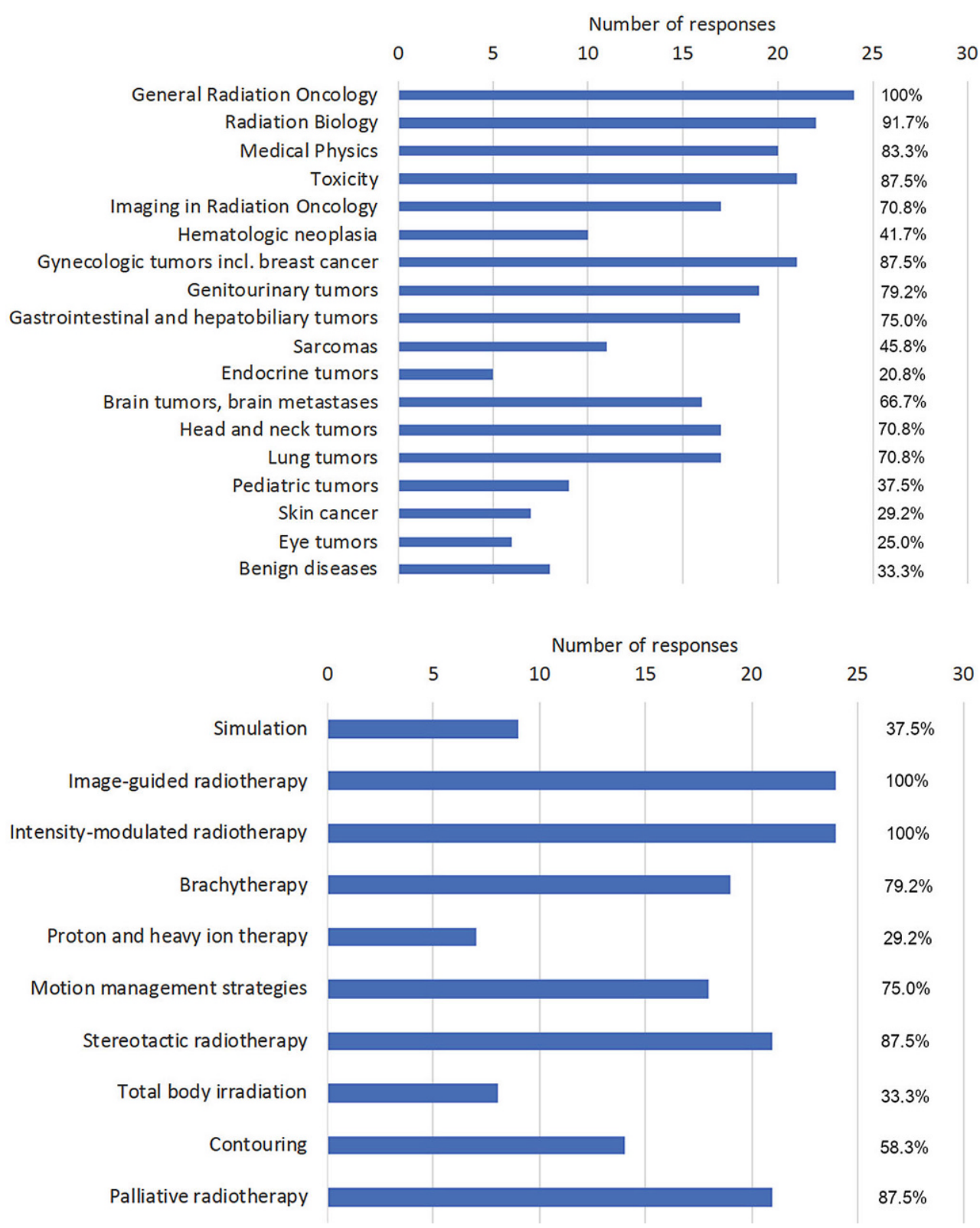

Fig. 3 Responses to the question "Which techniques and concepts are included in radiation oncology teaching?" Multiple answers were allowed ties, but only $70.8 \%$ offer a complete rotation (4 months). Elective teaching courses are offered at $75 \%$ of faculties covering additional subjects of RO. Essentially, $57.1 \%$ of radiation oncology faculties have taken measures addressing implementation of the Masterplan Medizinstudium 2020 and the accompanying NKLM for medical education.

\section{Discussion}

The presented survey describes the current situation of RO teaching in Germany and displays a variety of individual curricula with heterogeneity regarding extent, topics, and onset. 
Qualified teaching is of pivotal importance and a major factor for RO resident recruitment [8]. Additionally, RO education is highly relevant to medical students to provide oncological knowledge for later residency. However, the survey demonstrates heterogeneity in the extent and content of RO teaching throughout Germany. Some medical faculties perform seminars and lectures in one semester only or have no obligatory lecture at all, whereas others have developed extensive curricula with representation of RO in all clinical semesters.

Consequently, the spectrum of topics differs greatly. Whereas "RO in general/introductory lectures" are always held, only $70 \%$ of curricula include "lung," "head and neck," or "imaging in radiation oncology." "Hematology," "skin," "pediatric," or "endocrinology" received percentages below $45 \%$. It is particularly striking that only $1 / 3$ of medical faculties include benign diseases in their curricula. Interestingly, a comparable survey in 19 European countries, involving 32 academic institutions, showed a similar thematic selection with large heterogeneities in teaching extent (2-60h of RO teaching), the responding German institution being in the lower third [9]. Another analysis conducted in Australia and New Zealand unveiled a worse situation, with at least $50 \%$ of faculties, including $81 \%$ of students, not receiving training in basic principles of RO [10]. In summary, this minor role in the current curriculum does not adequately reflect the cardinal importance of the field in oncological patient care.

A disparity in knowledge of different entities persists even in RO residency, as displayed by a survey of the young DEGRO [11]. The implication may be discussed controversially: regarding the fact that many medical students will not choose oncological residencies, Haagedorn and de Vries argued for a change in teaching practice addressing the general practitioners' need for basic oncology education rather than focusing on details of biology and treatment [12].

What is the amount of RO teaching that is essential for every medical student? Which tumor entities should be mandatorily included in the curriculum of medical schools? These questions, amongst others, remain debatable and are currently being discussed by a new working group of the DEGRO (see below). It can be summarized that there is increasing consensus that a basic RO education for medical students should at least comprise the main oncological entities (breast, prostate, lung, head and neck, metastases in different locations ...) in Germany, as indicated by the cancer report of the Robert Koch Institute [1]. Moreover, it is our strong belief that practical training in oncological anamnesis, empathic counseling and guidance, and focused physical examination should be integrated.

In contrast to the vivid discussions on the overall scope of basic RO education during medical school, the teaching of RO techniques and concepts appears homogenous, with all faculties imparting the principles of modern image-guided and intensity-modulated RT. Only a minority of medical schools in Germany $(<30 \%)$ present particle therapy or heavy-ion therapy, which may be due to the limited distribution of the respective treatment facilities.

The abovementioned heterogeneity may be attributed to the different concepts of medical education. While the "regular" course teaches RO within the module "imaging procedures, radiation treatment, and radiation protection" together with radiology and nuclear medicine, the reformed or model curriculum (e.g., model curricula in Aachen, Berlin, Hannover, and Heidelberg and reformed curricula in Cologne and Muenster) aims at a concept-based education. Accordingly, organ-specific modules are established in which interconnectivity between the oncological disciplines takes center stage.

These challenges are being met by the DEGRO by the formation of a new working group focusing on the redefinition of learning objectives and key abilities in light of the new Masterplan Medizinstudium 2020. Its main goal will be the establishment of a national model curriculum for RO in medical education, serving as a blueprint for the individual faculties. A comparable schedule already exists for residents and will likely be refined within the near future [13]. Additionally, a reciprocal dialogue between RO and other disciplines, like surgery and internal medicine et cetera, will ultimately lead to a new interdisciplinary clinical schedule, strengthening cardinal aspects of RO.

The survey is restricted due to the rate of incomplete responses (2/3 responders), with a possible selection bias, as faculties more involved in teaching might have been more responsive to the survey. This might lead to a bias in the results and an underestimation of potential problems in the field of radiation oncology teaching. Furthermore, the evaluation and opinions offered for this survey may not represent a consensus of the whole teaching staff at the respective sites, as the survey was sent to the heads of the departments. Thus, the survey has to be seen as a punctual observation, which nevertheless may give suggestions for further improvements of RO teaching and implementation of new teaching concepts.

Recently, the German government introduced the Masterplan Medizinstudium 2020, summarizing a package of measures for structural reorganization [14]. Its main goals include the vertical integration between clinical and undergraduate subjects, the deepening and consolidation of scientific knowledge, as well as the introduction of competence-based learning [14]. Therefore, it corresponds with global trends towards competence-based medical education in accordance with today's medical students' desire for personalized, interconnected, and team-based learning [15, 16].

The formal requirements, as listed in the NKLM [6], call upon medical faculties and their teaching staff (es- 
pecially habilitated members) to thoroughly review their timetables, i.e., to change learning objectives from pure knowledge acquisition to practical application. Nevertheless, only a slight majority of faculties in the presented survey $(57.1 \%)$ have already taken measures concerning the NKLM, clearly calling for further action. Competencebased teaching may favor practical formats like bedside teaching or seminars over lectures, but lectures are still the predominant teaching format at present. Additionally, interdisciplinary formats, which cover different subjects and at the same time bridge clinical and undergraduate education, may gain even more importance in the future by providing an introductory multimodal overview [16-18]. A recently published example is the course "Anatomy and Imaging" at the University of Muenster transferring anatomy knowledge to its clinical application, like in RO [5, 20, 21].

The strategy of early integration of RO teaching may also be suitable to avoid misbeliefs in RO. A multi-institutional survey in the US showed deficiencies in knowledge concerning RO indications, toxicity, and techniques affecting first-year and fourth-year medical students [4]. An RO rotation could improve responses in all categories [4]. Considering this finding, the number of faculties offering a complete RO rotation (70.8\%) for final-year medical students should be increased. It is noteworthy that structured didactic sessions for clerkships could improve both students' knowledge and interest in the field, but also lead to better evaluation results [22-25], and should therefore be considered for the RO rotations in Germany.

Future efforts of the RO community should focus on an appropriate as well as interesting presentation of the discipline to medical students to avoid misconceptions, but also to attract potential RO residents. This topic has been addressed by several publications of our working group demonstrating the spectrum of RT clinical routine and research [26-28]. Corresponding to this, free-text comments within the current analysis revealed a spectrum of elective teaching formats offered to interested students, covering palliative care, pediatric radiation oncology, neuro-oncology, and more. This demonstrates the creativity of the RO teaching community in Germany as well as the vivid interest in implementing state-of-the-art teaching formats.

\section{Conclusion}

The current survey displays heterogenous curricula across Germany and emphasizes the need for a shift towards interdisciplinary and competence-based teaching formats. Shaping and defining a nationwide standardized curriculum with key abilities and knowledge of RO will be one of the key challenges for the DEGRO and the young DEGRO working group.
Funding Open Access funding provided by Projekt DEAL.

Conflict of interest M. Oertel, P. Linde, M. Mäurer, D.F. Fleischmann, and C.T. Dietzel declare that they have no competing interests. D. Krug has received honoraria from Merck Sharp \& Dome, outside of the submitted work.

Open Access This article is licensed under a Creative Commons Attribution 4.0 International License, which permits use, sharing, adaptation, distribution and reproduction in any medium or format, as long as you give appropriate credit to the original author(s) and the source, provide a link to the Creative Commons licence, and indicate if changes were made. The images or other third party material in this article are included in the article's Creative Commons licence, unless indicated otherwise in a credit line to the material. If material is not included in the article's Creative Commons licence and your intended use is not permitted by statutory regulation or exceeds the permitted use, you will need to obtain permission directly from the copyright holder. To view a copy of this licence, visit http://creativecommons.org/licenses/by/4. $0 /$.

\section{References}

1. Robert Koch-Institut (2017) Krebs in Deutschland für 2013/2014. RKI-Bib1 Robert Koch-Inst. https://doi.org/10.17886/rkipubl2017-007. Accessed 21 Jan 2020

2. Deutsche Krebshilfe (2019) Strahlentherapie. Die blauen Ratgeber, vol 53. Deutsche Krebshilfe, Bonn

3. Barton MB, Jacob S, Shafiq J et al (2014) Estimating the demand for radiotherapy from the evidence: a review of changes from 2003 to 2012. Radiother Oncol 112:140-144. https://doi.org/10.1016/j. radonc.2014.03.024

4. Zaorsky NG, Shaikh T, Handorf E et al (2016) What are medical students in the United States learning about radiation oncology? Results of a multi-institutional survey. Int J Radiat Oncol Biol Phys 94:235-242. https://doi.org/10.1016/j.ijrobp.2015.10.008

5. Oertel M, Schmitz M, Becker JC et al (2019) Successful integration of radiation oncology in preclinical medical education. Strahlenther Onkol. https://doi.org/10.1007/s00066-019-01492-z

6. Gesellchaft für Medizinische Ausbildung e.V (2015) Nationaler Kompetenzbasierter Lernzielkatalog Medizin (NKLM). http:// www.nklm.de/files/nklm_final_2015-07-03.pdf. Accessed 21 Jan 2020

7. Krug D, Baumann R, Rieckmann T et al (2016) Situation of young radiation oncologists, medical physicists and radiation biologists in German-speaking countries: results from a web-based survey of the Young DEGRO working group. Strahlenther Onkol 192:507-515. https://doi.org/10.1007/s00066-016-1003-y

8. Brower JV, Mohindra P, Bradley KA, Golden DW (2014) Radiation oncology residency selection: a targeted assessment of factor importance among fourth-year medical students. Int J Radiat Oncol Biol Phys 88:967-968. https://doi.org/10.1016/j.ijrobp.2013.12. 020

9. Mustapha BS, Meijnders P, Jansen N et al (2019) The status of radiation oncology (RO) teaching to medical students in Europe. Clin Transl Radiat Oncol 17:40-46. https://doi.org/10.1016/j.ctro.2019. 04.010

10. Nicholls L, Bravery B, Chelvarajah R et al (2018) The status of radiation oncology teaching in Australian and New Zealand medical schools. J Med Imaging Radiat Oncol 62:828-834. https://doi.org/ 10.1111/1754-9485.12788

11. Dietzel CT, Jablonska K, Niyazi M et al (2018) Quality of training in radiation oncology in Germany: Where do we stand? Strahlenther Onkol 194:293-302. https://doi.org/10.1007/s00066-017$1250-6$ 
12. Haagedoorn EM, de Vries J (1998) Topic selection in undergraduate medical education and relevance to general practice. $\mathrm{J}$ Cancer Educ Off J Am Assoc Cancer Educ 13:137-140. https://doi.org/10. 1080/08858199809528534

13. Akademie der DEGRO (2016) Curriculum zur Weiterbildung zum „Facharzt für Strahlentherapie“ der Akademie der „Deutschen Gesellschaft fur Radioonkologie“ (DEGRO) zur „Fort- und Weiterbildung in der Radioonkologie“, 2016. Deutsche Gesellschaft für Radioonkologie (DEGRO), Berlin

14. (2017) Masterplan Medizinstudium 2020. https://www. wissenschaftsrat.de/download/archiv/7271-18.pdf;. Accessed 4 Jan 2020

15. Carraccio CL, Englander R (2013) From Flexner to competencies: reflections on a decade and the journey ahead. Acad Med 88:1067-1073. https://doi.org/10.1097/ACM.0b013e318299396f

16. Desy JR, Reed DA, Wolanskyj AP (2017) Milestones and millennials: a perfect pairing-competency-based medical education and the learning preferences of Generation Y. Mayo Clin Proc 92:243-250. https://doi.org/10.1016/j.mayocp.2016.10.026

17. Dennis KEB, Duncan G (2010) Radiation oncology in undergraduate medical education: A literature review. Int J Radiat Oncol Biol Phys 76(3):649-655. https://doi.org/10.1016/j.ijrobp.2009.08.038

18. Agarwal A, Koottappillil B, Shah B et al (2015) Medical student-reported outcomes of a radiation oncologist-led preclinical course in oncology: a five-year analysis. Int J Radiat Oncol Biol Phys 92(4):735-739. https://doi.org/10.1016/j.ijrobp.2015.03.008

19. Agarwal A, Shah A, Shah B et al (2017) The impact of a radiation oncologist led oncology curriculum on medical student knowledge. J Cancer Educ. https://doi.org/10.1007/s13187-017-1227-2

20. Schober A, Pieper C, Schmidt R, Wittkowski W (2014) "anatomy and imaging": 10 years of experience with an interdisciplinary teaching project in Preclinical medical education-from an elective to a curricular course. RöFo. Fortschr Röntgenstr 186:458-465. https://doi.org/10.1055/s-0033-1355567

21. Schober A, Schmitz M, Zimmer S, Schmidt R, Oertel M, Vrachimis A, Marschall B (2017) Vom Know-what zum Know-how - 15 Jahre
„Anatomie und Bildgebung“. Joint Congress of the Gesellschaft für Medizinische Ausbildung (GMA) and the Arbeitskreis zur Weiterentwicklung der Lehre in der Zahnmedizin (AKWLZ), Münster, 20.-23.09.2017. https://doi.org/10.3205/17gma165

22. Golden DW, Spektor A, Rudra S et al (2014) Radiation oncology medical student clerkship: implementation and evaluation of a bi-institutional pilot curriculum. Int J Radiat Oncol Biol Phys 88:45-50. https://doi.org/10.1016/j.ijrobp.2013.10.041

23. Golden DW, Kauffmann GE, McKillip RP et al (2018) Objective evaluation of a didactic curriculum for the radiation oncology medical student clerkship. Int J Radiat Oncol Biol Phys 101:1039-1045. https://doi.org/10.1016/j.ijrobp.2018.04.052

24. Hirsch AE, Singh D, Ozonoff A, Slanetz PJ (2007) Educating medical students about radiation oncology: initial results of the oncology education initiative. J Am Coll Radiol Jacr 4:711-715. https://doi. org/10.1016/j.jacr.2007.06.011

25. Hirsch AE, Mulleady Bishop P, Dad L et al (2009) An increase in medical student knowledge of radiation oncology: a pre-post examination analysis of the oncology education initiative. Int J Radiat Oncol Biol Phys 73:1003-1008.e2. https://doi.org/10.1016/j.ijrobp. 2008.12.012

26. Oertel M, Mäurer M, Gauer T et al (2018) Strahlentherapie Mit vereinten Kräften gegen den Krebs. In: Thieme Medici Fachärzte Weiterbildungen. https://m.thieme.de/viamedici/arzt-imberuf-weiterbildungs-coach-fachaerzte-1571/a/strahlentherapiemit-vereinten-kraeften-gegen-den-krebs-34982.htm. Accessed 5 Oct 2019

27. Neuendorff NR (2019) Engagement für Weiterbildung, Forschung und darüber hinaus. Karger Kompass Onkol 6:106-112. https://doi. org/10.1159/000500533

28. Raspe M (2019) Von Zukunftsgestaltung und digitalen Tools. Karger Kompass Pneumol 7:95-98. https://doi.org/10.1159/ 000497262 